\title{
Sciences / Humans / Humanities: Dexter Masters' The Accident and Being in the Nuclear Age
}

\section{Daniel Cordle}

On 21 May, 1946, the Canadian physicist, Louis Slotin, was performing a criticality experiment at Los Alamos, New Mexico, the town that had been built to build the atomic bombs dropped on Hiroshima and Nagasaki the year before. Preparations were underway for the Operation Crossroads atomic tests in the South Pacific and the plutonium core with which he was working was intended for detonation at Bikini Atoll. ${ }^{1}$

The experiment, so perilous it was described as "tickling the tail of a sleeping dragon" by Richard Feynman (Lustig and Shepherd-Barr, 553), involved bringing the core to the point of criticality by gradually enclosing it in two halves of a beryllium shell. As the two halves of the shell were brought together, the beryllium reflected more and more neutrons back into the core, bringing it progressively closer to a selfsustaining chain reaction. Extraordinarily, all that prevented the shell from closing was a screwdriver, used by Slotin to hold up the top half of the shell. As it was gradually lowered, a Geiger counter gave an aural indication of increasing radioactivity.

Slotin had performed the experiment numerous times before, but this time his screwdriver slipped and, although he immediately knocked the top half of the shell away, he received a lethal dose of radiation and died nine days later. Seven other scientists, also in the room with Slotin, received radiation doses from the accident, although Slotin's swift actions, in breaking the apparatus, are often credited with saving their lives.

Slotin's gruesome death, early in the nuclear age - or, more precisely, the coding of that death in narrative - is revealing of concerns that have dominated the nuclear imaginary. The incident provides a telling example of the ways in which scientific knowledge, raw and processed materials and technological artefacts trouble our sense of self as we become nuclear. As a nuclear physicist killed by radioactivity, Slotin's nuclear becoming is clear to see, but there is a more widespread nuclear becoming after 1945 for which his death comes to stand symbolically (partly through the dissemination of radionuclides from atmospheric weapons testing, which enter ecosystems around the world, but perhaps more crucially through a psychological and cultural adjustment to living in a nuclear age).

Slotin's death has proven fascinating to writers. Probably the most sophisticated representation, on which I will focus in this article, is Dexter Masters' novel, The Accident (1955; reissued in a new edition in 1985 to coincide with the anniversary of the Hiroshima bombing), but versions of the experiment and the accident also feature in the novels Command the Morning (1959) by Pearl Buck, Stallion Gate (1986) by Martin Cruz Smith, Los Alamos (1997) by Joseph Kanon, The Gadget (2001) by Paul Zindels and Changing Light (2007) by Nora Gallagher. These cover a range of genres from the thriller, through young adult fiction, to literary fiction. The event also features in the film, Fat Man and Little Boy (USA, Roland Joffé, 1989), and is the subject of a play, Louis Slotin Sonata (1999), by Paul Mullin and a poetry sequence, Bloom (2010), by Michael Lista. 
Of course, radioactivity lab accidents, and variations thereof, have also been assimilated more broadly into popular, particularly comic book and film, culture. From the bite of an irradiated arachnid that turns Peter Parker into Spiderman at a public lecture on "Experiments in Radio-Activity" in the 15 August, 1962 edition of Amazing Fantasy (2-3), to the lab accident that transforms Jonathan Osterman into Dr Manhattan in Alan Moore and Dave Gibbons' complex alternative history, Watchmen (chap. 4, 7-8), the radiation accident has been imagined as the source of dramatic transformation from the wondrous to the sinister.

The cultural significance of the accident is rooted in the geopolitical symbolism of its geographical and temporal location (Los Alamos, the heart of the emerging nuclear state, on the cusp between the Second World and Cold Wars) and the quintessentially nuclear qualities of Slotin's death. It also provides an opportunity to reflect, in the context of this special edition of $J L S$, on the value of the ScienceHumanities and the Nuclear Humanities. The stress on the "Humanities" in this new terminology is instructive. ${ }^{2}$ As well as describing an interest in the cultural and social dimensions of the sciences, it signals a preoccupation with the ramifications of the human experience of science. It is, indeed, precisely the question of being human in the nuclear age that is the subject of The Accident.

We might understand the nuclear age as one dimension of the risk society described by the sociologists Ulrich Beck and Anthony Giddens in which, as Giddens puts it, "we increasingly live on a high technological frontier which absolutely no one completely understands and which generates a diversity of possible futures" (Giddens, 3). ${ }^{3}$ The human relation to the world, and the experience of being human, is different in such an age. It is not that the risk society is necessarily more dangerous than previous societies (though it may well be that), but that we have entered an era of technological modernity transformed by the "end of nature" (when almost all aspects of the natural world are touched by a human presence) and the "end of tradition" (the relinquishing of the belief that what happens to humans is simply fated by external forces). This is an age of "manufactured risk" which is "created by the very progression of human development, especially by the progression of science and technology" (Giddens, 4). Hence, the contemporary understanding of risk is born with Modernity and is "bound up with the aspiration to control and particularly with the idea of controlling the future" (Giddens, 3 ).

The Accident's focus on the nature of accident, on control and the loss of control, and on the alternative futures unleashed by the nuclear moment, make it a text preoccupied with risk in the sense described by Giddens. Moreover, these uncertain and proliferating futures continue to haunt the contemporary imagination. Continuing controversy about nuclear technologies (civilian and military), anxieties about the safe storage of nuclear waste tens of thousands of years into the future and, perhaps most of all, the re-emergence of the rhetoric of nuclear nationalism in a context of radical geopolitical uncertainty (most obviously, at the time of writing, in heightened tensions on the Korean peninsula), mean that The Accident remains strikingly resonant in the twenty-first century.

Before turning to it, I should say a few words about what approaching science from a literary perspective means. Fundamental questions for the ScienceHumanities are about how different kinds of expertise are constructed, how they function and what limitations there are upon them. These questions were at the heart of the "science wars" of the 1990s, when disputes about social constructivist approaches to science raged across the Science/Humanities interface. Harry Collins' work on the sociology of science is well worth reading in this regard for its balanced discussion of 
the ways in which scientific expertise is socially constructed (both from within and from outside science) and for its acknowledgement that, despite this, science should, as he says with his co-author Robert Evans in Rethinking Expertise, "be treated not just as a resource, but as a central element of our culture" (Collins and Evans, 11).

Literary studies may seem to have an even more precarious claim to legitimacy than sociology in its engagement with science. Yet, as long as it is clear what claims it is making, there is a strong case for seeing it as having an important role to play in the ScienceHumanities. In an earlier work I argued for the value, in literature-science studies, of distinguishing between "professional science," that set of practices, languages and expertise comprising the life of the working scientist, frequently not directly accessible to Humanities scholars without specialist training, and "cultural science," the presence in the world of translations and mistranslations of professional science, as well as a body of artefacts and technologies with which they are associated (Cordle, 51-53). ${ }^{4}$ With Slotin's death and its subsequent translation into narrative we have a case in point here of modes of knowing shifting between professional and cultural science.

While there is much of the story that might be deemed truly accessible only to those with a scientific training (the processes by which the core went critical; the physiological impact on Slotin's body of exposure to ionizing radiation), when it enters narrative it becomes culturally potent. Masters' novel provides a case study of sense-making in an atomic age: the cultural processing of nuclear knowledge, experience and artefacts into meaning. In its retelling, Slotin's death troubles our idea of risk; it troubles too our idea of the human.

\section{Dexter Masters' The Accident}

Masters' novel is an interesting hybrid of fiction and history. It follows events between the accident and the death that follows it several days later, correlates directly in various ways with what happens to Slotin, but introduces enough overt differences to give Masters the artistic freedom to explore an emerging nuclear consciousness in the mid-1940s. It was a significant volume when it was first published and had some notable international impact, being translated into thirteen other languages (Schonberg, np). ${ }^{5}$ It was also deemed subversive enough for the State Department effectively to ban a planned film of it by refusing an export licence, as Masters explains in his foreword to the 1985 edition (Masters, vii-viii).

It is worth noting that although, as I will detail, Masters changes Slotin's story significantly, he does so from an informed perspective. With the physicist Katharine Way, who worked in Chicago on the Manhattan Project, Masters was co-editor of One World or None (1946), an important volume of essays explaining atomic technology and its geopolitical implications to the general public. This volume, a collaboration between a writer/editor and a scientist, usefully reminds us that the ScienceHumanities has a long prehistory.

Way records, in a 1982 letter to the Bulletin of the Atomic Scientists (Way, 49), how she and Masters arrived at an impressive list of scientific contributors, including Albert Einstein, Eugene Wigner, J. Robert Oppenheimer (leader of the scientific project at Los Alamos), Harold Urey, Arthur Compton, Niels Bohr and Leo Szilard (who had been one of the first to see the potential of nuclear chain reactions and the terrible possibility of a Nazi bomb). The volume emphasises the revolutionary implications of atomic technology. Hence, in his introduction Compton suggests a stark choice between an "outworn tradition of national self-defence," resulting in "catastrophic conflict," and "adjusting the pattern of our society on a world basis so 
that wars cannot come again" (Masters and Way, xiii); Bohr argues in his foreword that national self-defence is meaningless in an atomic age without "worldwide cooperation to prevent any use of the new sources of energy" (Way and Masters, xviii); and Einstein warns that now "all the people living in cities are threatened, everywhere and constantly, with sudden destruction" (Way and Masters, 209). In the book's final essay, a statement by the Federation of Atomic Scientists asserts that the "arms race must be stopped" for the world's nations cannot "do otherwise [than collaborate on developing atomic power] and live" (Way and Masters, 217). Masters was, then, an informed thinker on nuclear risk. He was familiar with the people who had made the bomb and knew how it troubled many of them.

In his novel, Louis Slotin is transformed into Louis Saxl. Like Slotin, Saxl is the descendent of Jewish immigrants to North America (an important consideration, given that the initial impetus for the Manhattan Project was the fear of a Nazi atomic weapon), though Masters has him as the grandson of German immigrants to the US Midwest, rather than the son of Russian immigrants to Canada. Like Slotin, Saxl is in Spain in the 1930s, though caught up more directly in fighting Franco's fascist forces than Slotin who, though the biography is ambiguous here, seems merely to have been "in" Spain at the time of the civil war. Instead of getting his doctorate in London in the mid-1930s, Saxl receives his in 1939 from Columbia University, New York, on the eve of World War Two.

Whereas Slotin spends time during World War Two (at Oak Ridge, Tennessee) with Eugene Wigner, who, with Edward Teller and Leo Szilard, had engaged Einstein's support to alert the US government to the possibility of a German atomic bomb, Saxl first encounters the idea of the bomb when he hears senior faculty at Columbia discussing Einstein's letter to Roosevelt. Like Slotin, Saxl spends time, after his doctorate, in a poorly paid job at the University of Chicago where he's involved with building the cyclotron and from which he is later recruited for the Manhattan Project.

These subtle shifts in the back story - that he is a US rather than a Canadian citizen; that he fights on the Republican side (presumably in the Abraham Lincoln Brigade) in the Spanish Civil War; that he is closer at Columbia to the initial stages of the Manhattan Project - put Saxl more in the thick of the forces that politicise nuclear science in the late 1930s and early 1940s. Crucially, of course, like Slotin, he ends up at Los Alamos, and like Slotin he is directly involved in assembling the bomb for the Trinity test. Nine months before their own deaths, both Slotin and Saxl witness the slow deaths of their colleagues in a radiation accident (Harry Daghlian in reality; Nolan in the novel). As in reality, the plutonium core that kills Daghlian/Nolan is the same one that later kills Slotin/Saxl. However, the details of the accident are slightly different. Whereas Slotin was enclosing a plutonium core in two hemispheres of beryllium, Masters has Saxl adding blocks to a pile of fissionable material. This is closer to, though slightly wrong in its representation of, the accident that killed Daghlian than to the one that killed Slotin (Daghlian wasn't moving fissionable material itself, but positioning blocks of a tungsten carbide tamper around it when he dropped one on the plutonium core). After the accident, like Slotin, Saxl spends his last excruciating days in the same hospital bed in which Daghlian/Nolan died nine months previously.

Many of these changes were, no doubt, an exercise in discretion. Masters was, after all, fictionalising the final days of a man who had died relatively recently and was, moreover, a colleague of some of those who had contributed to One World or None. To make changes was to free Slotin from inferences that might specifically be 
made about him through Saxl; it was also to free the novel from the necessity of a supporting cast of colleagues, friends and family who were still alive. Yet, so much remains a ghostly echo of Slotin's fate that it is clear Masters wants us to find meaning in the incident.

The novel, Modernist in form as it melts between past and present, is structured around Saxl and particularly Saxl's body. The accident occurs in the opening pages and the remainder of the narrative takes place over the days it takes him to die. As he lies in the hospital bed we discover, through his reminiscences, the paths that led him to Los Alamos and his disquiet at being drawn into a project in which science ceased to be the idealistic and disinterested pursuit of knowledge. This echoes qualms about the Bomb, and the desire for greater reflection and discussion before its use, expressed by scientists like Joseph Rotblat and Leo Szilard. After the war such qualms amongst nuclear physicists found expression both in the founding of the Bulletin of the Atomic Scientists (and its famous Doomsday Clock, which first appeared on the cover in 1947) and, of course, in the publication of Masters and May's One World or None.

In the novel, we also follow Saxl's fiancé and family as they travel from different parts of the United States, arriving just before his death, and the quiet struggle, outside the hospital, between his friend and colleague, David Thiel, and the military commander of the project, Colonel Hough, over control of public knowledge about his death. As the novel progresses, he is transformed, in a crucial motif, from a human being to a lab rat; indeed, he quickly becomes aware that the circumstances of the accident situate him uniquely as a test subject for the study of radiation sickness.

\section{"Seeing" Radioactivity}

One of the key challenges narrative faces in representing a world imagined as nuclear, ${ }^{6}$ is making radioactivity - colourless; odourless - visible or otherwise apprehensible to our senses. We only see it symptomatically and indirectly, through the traces it leaves on its journey through the environment or in changes to that environment over the lifetime of radioactive decay. Narrative is, of course, always all signifier, but with radioactivity the signified is doubly distanced from us: linguistic signifiers can only represent indirect signifiers of radioactivity, not radioactivity itself: the click of a Geiger counter; the collapse of Saxl's body over the course of a week. This is, of course, a special case of the different ways of seeing in operation in the Sciences and the Humanities discussed earlier. It is through the various narratives that accrete around radioactivity that it begins to acquire meaning and make sense culturally. Such meanings may (or may not) be distortions of scientific knowledge (for example, through misapprehension, as in a disproportionate estimation of the danger posed by radioactivity, or through lack of precision, as in the conflation of radiation with radioactivity), but they are nevertheless significant dimensions of cultural science as defined above.

A powerful way to work through the consequences of these narrative manifestations of phenomena associated with scientific understanding is to find a vocabulary with which to theorise them. For example, elaborating on Sigmund Freud's notion of the uncanny, Joseph Masco has conceived of a psychological phenomenon of the "nuclear uncanny [which] exists in the material effects, psychic tension, and sensory confusion produced by nuclear weapons and radioactive materials" (Masco, 28). There is indeed a strong sense of the uncanny in The Accident. Saxl's experience of increasing alienation from his own body is reproduced in several moments of uncanny terror. 
For instance, immediately before the accident, a soldier, on guard outside the laboratory, ${ }^{7}$ is disturbed by the clicking of the Geiger counter: "He cannot hear it without restiveness, for he knows enough about what goes on inside to know that the sound is a measurement of dangers, bad dangers, and all the worse because he doesn't know just what they are" (19). The soldier is there to protect the valuable plutonium core from outside threats, but the real danger is within - and it is not a danger for which a soldier is equipped to deal. When he hears a rapid and unexpected rise in the clicking of the counter and hears a shout from within the room, it is a significant detail, given it is the nature of uncanny terror to reside in the known and familiar, that, although he realises "something is very wrong," the "flowers that edge the clearing gently sway in a normal breeze" (20).

The unnamed soldier's perspective is the only one from which we perceive the accident. His perspective, from outside, is significant too, perhaps, for the way it echoes the lay reader's sense of being an outsider in this new world; of, like the soldier, suspecting "dangers" but not really knowing "just what they are." In any case, we miss the key moment of the novel: the instant when everything changes for Saxl. When the soldier rushes in he is confronted with a still-life tableau of the seven scientists in the room: "none of them moves, no one turns to look at him, each stands motionless as though he has a part to play in a game of Living Statues. Six of them, rooted here and there about the room, are looking at the seventh, Louis Saxl" (21).

There is a freezing of time here, a struggle to preserve knowledge of what has happened. Perhaps there is an echo too, in this tableau of a frozen moment, of the blast shadows cast by human bodies when the atomic bombs exploded over Hiroshima and Nagasaki and from which, also, those more dramatic nuclear moments could only be imperfectly reconstructed. ${ }^{8}$ Although those present in the laboratory seek to fix the moment by remaining motionless, the real protagonist, the radioactivity, is already working its damage within their bodies. The moment of the accident, the cusp of change, has been and gone in a fraction of a second before it can be apprehended - and, in any case, the narrative point of view through which this scene is focalised, has arrived, in the form of the soldier, several seconds too late to see what happened. Just minutes later, one of the witnesses can only say, "I can't tell you [why it happened], I don't know, except he lost control. ... I don't know why" (23). Thiel comments mysteriously that the accident was a slip of "the mind and heart, maybe, but not of the hands" (32) as if it were the external manifestation of a deep psychological unease.

The issue of what is unknown is a preoccupation of the novel. In part, this is about the new phenomenon of radiation sickness, for which Saxl will become an experimental subject. Indeed, part of the mythology of Slotin's death, reproduced in the novel, is that in the seconds immediately following the accident he asks everyone to stay still while he coolly sketches where they are, aware that his personal catastrophe will furnish valuable data about this new kind of death. Gruesome footage of Slotin's death was in fact used in courses on the dangers of radioactivity (Schlosser, 416), another sense in which the incident prompts ways of seeing, in this case a "seeing" of radioactivity through its corporeal signifiers.

\section{Problems of knowledge}

Saxl's illness presents a problem to the medical staff who care for him. It is not merely that they cannot save him, it is that what happens to him confounds their understanding. Betsy, a nurse, is frustrated not merely by her lack of experience in radiation sickness, but by the fact that it does not seem amenable to normal 
approaches by which she might seek to understand it: "she knew not what to get hold of, or where to look for meanings, in the mysteries of radiation sickness" and it "bothered her that this sickness was more comprehensible to physicists and chemists than to doctors and nurses, and seemed truly comprehensible to no one" (71).

Saxl's colleague, Thiel, is frustrated and upset by the way in which his friend is transformed into a test subject. As he reflects, the military's interest in Saxl and his colleagues is due to the medical data they will furnish that could not be extracted from Hiroshima and Nagasaki: "Seven aren't worth a hundred thousand [atom bomb victims] ... [e]xcept as they provide the first completely observed and measured cases of acute radiation syndrome in history - nicely graduated too, from intense to negligible exposure." As he comments bitterly: "what a full set of curves and charts and graphs we'll get from Louis! How greatly we'll enrich the literature!" (128).

In a private moment, Louis reflects about this "literature": "Books and journals, books and journals, he repeated to himself. Everybody will be reading something, mostly about mice and dogs because there isn't very much about us humans" (118). The bombings in Japan, he muses, were of little use because there were so many variables and because those with the medical knowledge to collect and interpret the evidence were themselves killed: "[o]ut of eight hundred and fifty medical students in Nagasaki, six hundred killed outright" (119). This leads him to an important insight into the critical interpretation of texts:

The important thing about reading a [medical] chart is to read no more than is there. The important thing about reading how six hundred out of eight hundred and fifty medical students were killed in a city of secondary importance bombed without warning is to read more than is there. (119)

He perceives here the necessity for discretion in reading. Out of raw facts different meanings will emerge depending on the interpretative strategies brought to bear. By reading ethically - by reading "more than is there" - he is able to put the statistic from Nagasaki into a human context. In many ways, this is what Masters is himself doing with the raw "facts" of Slotin's death: he is indeed finding "more than is there" (even contradicting known information and making things up), but it is by doing this that he is able to explore the human experience of the atomic age. This turning of the event into narrative is a small example of a much broader set of creative responses to the nuclear age and, by extension, signals an important role for the ScienceHumanities, promoting, interrogating and making sense of this processing of science, technology and their consequences in human terms.

Just as John Hersey's iconic article, "Hiroshima," for The New Yorker in 1946, humanised a Japanese enemy who had become monstrous in wartime propaganda, and who were themselves subject to objectification as case studies in radiation sickness, ${ }^{9}$ so Masters carefully reinserts the human experience into an event that might otherwise be a grotesque anecdote about nuclear safety. Privy to Saxl's reminiscences in the hospital bed, we become aware what of him is missed by the careful recording of data and what of him cannot be preserved by the photographer's pictures of his body's decline.

The novel thus opens up territory beyond the physiological consequences of radiation exposure. What is at stake here, as for the ScienceHumanities more generally, is the human experience of a world shaped by scientific modes of knowing and their technological and other real-world consequences. As well as being interested 
in what is missed by scientific modes of knowing, it reveals also the violence that narrative modes of knowing do to the complexity of Saxl's lived experience.

A case in point is provided by attempts to interpret Saxl's swift breaking of the experimental apparatus as the accident happens. Colonel Hough seeks to assert control over this moment by imposing a heroic narrative on it. In a revealing scene he and his wife work on a press release:

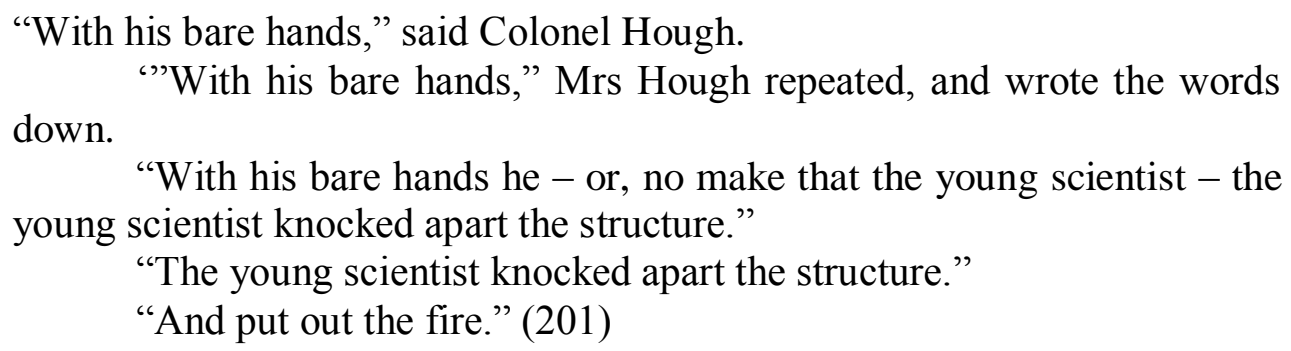

Two things are significant here. First, Hough is trying to convince others, and perhaps himself, that a decision made in a fraction of a second before it can consciously be apprehended is heroic. This is a more psychologically appealing narrative because it reasserts the role of human agency in bringing the chain reaction under control. Yet, the swiftness of Saxl's actions, preceding conscious decision, problematize not simply the desire to see him as heroic, but our sense of the relation between mind and brain. Elsewhere in the novel, a cynical engineer, confronted with Hough's story, points out that the "trouble with the Colonel is that he just can't visualize a millionth of a second" (55). Second, Hough's mistaken conception of the chain reaction as a "fire" reveals how much the nuclear moment confounds prior experience; elsewhere other characters refer to the incident, also erroneously, as an "explosion" (45).

These suggest the qualitative newness of nuclear experiences. People try to make sense of them with narrative formulations that are pre-nuclear. In other words, they are mediated through stories and mythologies that predate what we might crudely designate the nuclear age. This is an ongoing challenge and part of the reason for the peculiar cultural associations of the nuclear, especially of radioactivity, with the mysterious, the magical and even, sometimes, the malign. As Spencer Weart long ago pointed out, disparate nuclear imagery is often connected by an underlying preoccupation with an idea of transmutation deeply rooted in Western mythologies. ${ }^{10}$

In the novel we see the clash of pre-nuclear and nuclear ways of seeing (as well as a more general anxiety about what laboratories signify to outsiders), when Thiel takes Saxl's father to the radiation laboratory to see the plutonium pile that caused his son's illness. Mr Saxl struggles to make sense of what he sees. A carpenter, he tries to understand his son's job through his own working experience, but can "make nothing of the cube-shaped pile that he understood to be the machine that had gone wrong in his son's hands." Like the misunderstandings about the accident as an "explosion" or "fire," Mr Saxl's conception of the plutonium pile as a "machine" indicates the conceptual challenge he faces in understanding his son's death. Conjuring up an artefact comprised of moving parts, the word shows the inadequacy of a vocabulary rooted in the mechanical age for making sense of the subatomic processes at play in nuclear materials and technologies. How can something that, to his eyes, is inert and unchanging, have effected such a catastrophic change in his son?

Indeed, the blandness of the laboratory scene, its absence of visible complexity, confounds Mr Saxl's senses. The plutonium pile sits on a table very like the one in his workshop, yet it signifies in confusing ways: 
There were familiar objects on the table too - pencils and tools and the rest. But with the gray brick pile he could find nothing from which to start a thought; it had no front, or else it was all front and so equally all sides; he could barely make out some of the lines of the edges of the bricks; his eyes reported the unbroken smoothness of the surfaces; and this made his mind uneasy more than anything. (318)

What is described here as evoking uneasiness is surely, in Masco's terms, another uncanny encounter: a curious and disturbing juxtaposition of the familiar and the unfamiliar. The pile seems both straightforward and inexplicable; it seems formless and to defeat the rules of perspective by which his eyes might make sense of it. Indeed, confronted with it, Mr Saxl's senses seem untrustworthy. The phrase "his eyes reported" is revealing: what his eyes see no longer makes instantaneous sense; the process of seeing gives him no clue to the function of the thing he sees; the "report" from his eyes is inherently untrustworthy.

\section{Conclusions}

The novel hence presents entry into the nuclear age as a peculiarly troubling transition, not only for Saxl but for others too. In part, it is about new kinds of risk, knowledge and experience and our struggle to process them with vocabularies and conceptual frameworks that predate them.

Perhaps Slotin's actual death is limited in what it reveals about ongoing nuclear dangers. Although his conduct of the experiment was inherently risky Enrico Fermi had already warned him that he would be "dead within a year" if he persisted with it (Wallerstein, np) and Mahaffey suggests that Slotin (unlike Saxl) was an inherent risk-taker (Mahaffey, loc. 1350) - it was atypical and unnecessary. His working practices were out-of-date hangovers from the urgency of wartime and the experiment was never repeated in the same way again.

Yet the broader possibility of unintended consequences, to which the accident gestures, is a concern raised by the novel. To use a loaded Cold War term, these are often problems of containment. On the local level, we see the impossibility of containing radiation sickness once Saxl is ill. His body collapses in ways that are hard to comprehend. Colonel Hough, for instance, working with an inadequate paradigm of infection, struggles to understand why the sickness cannot be contained: "Would it be possible ... by amputating the hands...- With gangrene and things like that, if they amputate in time they stop it from spreading" (28).

Elsewhere the novel alludes to the unexpected spread of radionuclides from the Trinity Test of 16 July, 1945. Masters has three scientists discuss over lunch a newspaper story about the "Eastman Report" (147). ${ }^{11} \mathrm{He}$ is drawing on a specific newspaper story for this detail. On 23 May (seven days before Slotin's death), the New York Times published an article, "Film Spots Trace Vast A-Bomb Range," a follow-up to a mystery raised in a piece in early November, 1945, "Radioactive Crop Stirs Atom Study." The photographic film company, Eastman Kodak, had received complaints in the summer of 1945 that their film was fogged. Investigations revealed that radioactive fallout from the Trinity Test had spread thousands of miles, contaminating strawboard manufactured in the Midwest used as packaging by Eastman Kodak (and hence partially exposing the film). The paper also reported raised levels of radioactivity in Maryland and Arizona. As the newspaper announced, 
"temporarily radioactive by-products of a single bomb spread in the course of a few days over an area about the size of Australia" (Sullivan, 1).

Another problem of containment alluded to by the novel is that of the spread of nuclear secrets. A paranoid Congressman insists guards are stationed in Saxl's hospital room lest he blab nuclear secrets in his delirium (308). Elsewhere, in a wonderfully understated moment, the (actual) spy Klaus Fuchs is mentioned as being helped with a faulty car by a soldier (80). Nuclear materials and information are leaking from the site.

These various anxieties of containment and risk - of physiological contamination of a particular body, of a more broadly dispersed geography of consequences, and of the control and distribution of specialised knowledge - point not only to the concerns of the nuclear age that run far beyond Saxl's/Slotin's particular circumstances and remain pressing in the twenty-first century, but also to the broader preoccupations of the ScienceHumanities. Certainly, Masters finds the events he fictionalises instructive beyond Saxl's/Slotin's individual fates. He dedicates the first edition of the novel to Slotin and to the dead of Hiroshima and Nagasaki; in the 1985 edition he extends this dedication to those sick and dead as a result of subsequent nuclear testing. In a new foreword to that edition, he extends the relevance of the story still further when he conjures the potential nuclear futures we all face (futures that were particularly pressing during the Cold War nuclear standoff, but that have not disappeared now), writing that "all of us now confront his [Saxl's] fate. It may be that we can avoid his fate, but that fate insists on being confronted" (x).

Saxl hence becomes an emblematic nuclear subject. His body becomes (literally so) nuclear. The novel presents this as a peculiarly contemporary experience, qualitatively different from that of pre-existing illnesses and accidents. It is perhaps worth noting that while Saxl's/Slotin's fate was extreme, there was a shared corporeal nuclear subjectivity around the globe: widely reported studies found the presence of strontium-90 (a radioactive by-product of nuclear testing that the body metabolises like calcium) in human bones and teeth around the world. ${ }^{12}$

More broadly, though, it is by telling the story of Saxl's nuclear experience that Masters broaches more far-reaching questions. When Saxl describes uranium as the "birthstone of the Twentieth Century" (271), it is to suggest that, despite his death, something is being born at Los Alamos. One of Saxl's doctors describes Los Alamos as "a laboratory of opposites, extremes, even cross-purposes." It is, he says, "one of the biggest and best-equipped scientific laboratories in the world and the biggest arms factory, and therefore [one should think of it] as a kind of double symbol of the future and the nonfuture of the world" (303).

This duality describes the extremes of potentiality inherent in the risk society described by Beck and Giddens, discussed earlier. The ScienceHumanities surely provide a potent explanatory force for making sense both of this society and of a world more generally shaped by scientific modes of knowing, scientific knowledge and the technological consequences that follow. They deal with the human experience of, and interaction with, this world.

This conception of the ScienceHumanities is neither as dispensable adjunct to, nor as imperialistically explanatory of, the Sciences. It is a vision of the ScienceHumanities as embedded in the complex webs of discourse and explanatory frameworks that comprise human knowledge. Far from trying to find bridges between two entirely separate modes of knowing, it conceives of itself as mapping knowledge practices that are always already tangled up with each other. In such a world, where science is always social and cultural (which is neither to say that it is necessarily 
socially and culturally arbitrary, nor that "truth," such as it is, is always relative), the Humanities cannot but be the ScienceHumanities. It is inconceivable to study human experience and human knowing outside the Sciences and outside their effects, direct and indirect, upon the world.

Perhaps the great contribution of prose fiction over the centuries has been as a series of exercises in empathy: the provision of narrative structures by which we might know, in a sophisticated sense, how others know the world. Masters' The Accident takes us into the human experience of a fictionalised Slotin, and of those who knew and loved him. Many of them also thought deeply about the complex and ambiguous consequences of the extraordinary scientific and technological enterprise with which he, and some of they, were involved.

One contribution of the Nuclear Humanities and of the ScienceHumanities is to understand these processes of sense-making and to draw out the complex means by which the idea of the human inhabits, and is changed by, the world we are creating. The novel leaves us suspended before the alternate nuclear "futures" and "nonfutures" Saxl's doctor sees at Los Alamos. It shows how entangled our sciences and our technologies are with human experience. In some cases their material consequences might, as in the ingestion of radioactive byproducts of nuclear weapons testing noted above, even infiltrate our bodies. Regardless, they change our sense of who we are and mediate our identities. Our sciences and our technologies are our culture and they are our selves. 


\section{Notes}

1. There is some dispute about the eventual destination of this plutonium core. Eric Schlosser claims that it was eventually detonated over Bikini Atoll (Schlosser, 95), while Alex Wellerstein (Wallerstein, np) says that Los Alamos records show it was melted down to be made into a new weapon.

2. The term "ScienceHumanities" originates with a project at Cardiff University that began with an international colloquium in December 2016. The "Nuclear Humanities" was the subject of a workshop at the University of Liverpool in April 2017.

3. See also Beck.

4. This model does not presume a one-way flow of influence from professional to cultural science. Scientists' starting presumptions about the world, funding for projects and access to scientific training are all shaped by the cultural and social contexts within which professional science operates.

5. The full title of Schonberg's obituary of Masters incorrectly says that he is British. A correction on 7 Jan. 1989 gives his nationality correctly as American.

6. It is important to remember that the world does not, of course, become nuclear in 1945, for nuclear phenomena and processes are intrinsic to the universe, and human explorations of those phenomena predate atomic technologies. Rather, the world is more intensely apprehended as nuclear after 1945.

7. This is a significant tweak to reality. There was actually a guard inside the room (Wallerstein, np), looking after the plutonium. By placing the narrative perspective outside, Masters increases our sense of the unknowability of the accident.

8. I am grateful to Keir Waddington for this illuminating suggestion.

9. Although the original piece is available online at <www.newyorker.com/magazine/1946/08/31/hiroshima> [accessed 22 Sep. 2017], it is worth also reading the additional chapter, "The Aftermath," that is added to the 1985 edition of the book and which recounts the experiences of bomb survivors who, like Saxl, became experimental subjects.

10. See Weart, 391-428.

11. Later, at a party, one character wonders, in the light of the Eastman report, if plans for "building [atomic] piles all over" can be safe (Masters, 154).

12. This was most famously demonstrated through studies of children's milk teeth. See, for instance, the Washington University School of Dental Medicine's online exhibit about the collection of nearly 300,000 milk teeth from children which showed that "radioactive strontium-90 levels in the baby teeth of children born from 1945 to 1965 had risen 100-fold" ("St. Louis Baby Tooth Survey, 1959-1970," np). See also Steven Spencer's claim in an article for the Saturday Evening Post that "every living creature, man included, has in its bodies a few particles of radioactive strontium 90" from weapons testing (Spencer, 26). 


\section{Works Cited}

Beck, Ulrich. Risk Society: Towards a New Modernity. Translated by Mark Ritter, Sage, 1992.

Bohr, Niels. "Foreword: Science and Civilization." One World or None: A Report on the Full Meaning of the Atom Bomb, edited by Dexter Masters and Katharine Way, The New Press, 2007, pp. xv-xx.

Collins, Harry, and Robert Evans. Rethinking Expertise. U of Chicago P, 2007.

Compton, Arthur H. "Introduction." One World or None: A Report on the Full Meaning of the Atom Bomb, edited by Dexter Masters and Katharine Way, The New Press, 2007, pp. xii-xiv.

Cordle, Daniel. Postmodern Postures: Literature, Science and the Two Cultures Debate. Ashgate, 1999.

Einstein, Albert. "The Way Out." One World or None: A Report on the Full Meaning of the Atom Bomb, edited by Dexter Masters and Katharine Way, The New Press, 2007, pp. 209-14.

Federation of the Atomic Scientists, The. "Survival is At Stake." One World or None: A Report on the Full Meaning of the Atom Bomb, edited by Dexter Masters and Katharine Way, The New Press, 2007, pp. 215-20.

Giddens, Anthony. "Risk and Responsibility." The Modern Law Review, vol. 62, no. 1, 1999, pp. 1-10.

Hersey, John. Hiroshima. Penguin, 1985.

Lee, Stan, et al. Amazing Fantasy. No. 15, Marvel Comics, Aug. 1962.

Lustig, Harry and Kirsten Shepherd-Barr. "Science as Theater." American Scientist, vol. 90, no. 6, 2002, pp. 550-55.

Mahaffey, James. Atomic Accidents: A History of Nuclear Meltdowns and Disasters from the Ozark Mountains to Fukushima. Pegasus, 2015. [Kindle book]. Retrieved from www.amazon.com.

Masco, Joseph. The Nuclear Borderlands: The Manhattan Project in Post-Cold War New Mexico. Princeton UP, 2006.

Masters, Dexter and Katharine Way, editors. One World or None: A Report on the Full Meaning of the Atomic Bomb. The New Press, 2007.

Moore, Alan, and Dave Gibbons, Watchmen. No. 1-12, DC Comics, 1986-87.

Schlosser, Eric. Command and Control: Nuclear Weapons, the Damascus Accident, and the Illusion of Safety. Penguin, 2014. [Kindle book]. Retrieved from www.amazon.com.

Schonberg, Harold C. "Dexter Masters, 80, British Editor: Warned of Perils of Atomic Age.” The New York Times, 6 Jan. 1989. www.nytimes.com/1989/01/06 /obituaries/dexter-masters-80-british-editor-warned-of-perils-of-atomic-age .html?mcubz. Accessed 19 Sep. 2017.

Spencer, Steven. "Fallout: The Silent Killer." The Saturday Evening Post, 29 Aug. 1959, pp. 26-27.

“St. Louis Baby Tooth Survey, 1959-1970." beckerexhibits.wustl.edu/dental/articles/ babytooth.html. Accessed 21 Sep. 2017.

Sullivan, Walter S. "Film Spots Trace Vast A-Bomb Range: Radioactive Particles Spread Over Australia-Sized Area, Eastman Studies Show." The New York Times, 23 May 1946, p. 1, p. 3.

Way, Katherine. "One World or None: For the Record." The Bulletin of the Atomic Scientists, vol. 38, no. 2, Feb 1982, p. 49.

Weart, Spencer R. Nuclear Fear: A History of Images. Harvard UP, 1988. 
Wellerstein, Alex. "The Demon Core and the Strange Death of Louis Slotin." The New York Times, 21 May 2016. www.newyorker.com/tech/elements/demoncore-the-strange-death-of-louis-slotin. Accessed 18 Sep. 2017. 